\title{
Generalized edema as the dominant clinical symptom of celiac crisis
}

\author{
Dominika Wilczyńska, Martyna Rekowska, Dorota Lewandowska, Joanna Wyrębska-Ruge, \\ Aneta Krogulska, Anna Szaflarska-Popławska \\ Department of Pediatrics, Allergology and Gastroenterology CM Bydgoszcz, NCU Torun, Poland
}

\section{ABSTRACT}

Celiac disease (celiac disease) is an autoimmune systemic disease caused by the consumption of gluten in genetically predisposed individuals. It is estimated that the incidence of celiac disease is constantly increasing and currently it is seen in $1 \%$ of the pediatric population. According to the latest classification, there are classic, non-classical, subclinical and potential forms of celiac disease. In this publication, we present the rare form of celiac disease, which is the classic form in a 2-year-old boy. In children with classic celiac disease the most common clinical picture is chronic diarrhea, abdominal pain, impaired physical development and enlarged abdominal circumference. In the presented patient, the clinical picture was dominated by rapidly increasing edema and laboratory tests showed abnormalities - hypoalbulinemia, ionic disturbances, anemia and disorders of the coagulation system.

In a child with generalized edema the differential diagnosis should include the classic form of celiac disease.

\section{KEY WORDS:}

celiac disease, edema, classic celiac disease, celiac crisis.

\section{INTRODUCTION}

Celiac disease (celiac disease) is an autoimmune systemic disease caused by the consumption of prolamines in genetically predisposed individuals. Prolamines, conventionally called gluten, contained in wheat, rye and barley, induce immunological reactions leading to damage of the mucosa of the small intestine and development of enteropathy [1-4]. It is estimated that the incidence of celiac disease is constantly increasing and currently it is seen in $1 \%$ of the pediatric population [2, 5-9].

Celiac disease is characterized by various manifestations, depending on the clinical form of the disease. According to the latest classification, there are classic, non-classical, subclinical and potential forms of celiac disease $[2,10]$. The classic form of the disease, which is more common among children under 2 years of age, is associated with impaired intestinal absorption, chronic di- arrhea, dehydration, electrolyte disturbances, poor weight gain or weight loss, growth failure, malnutrition / cachexia and edema secondary to hypoalbuminemia [2, 10-12]. A rare complication of celiac disease may be the celiac crisis, which is a life-threatening condition.

In this publication we present the rare and the heaviest form of celiac disease, which is the celiac crisis of a 2-year-old boy.

\section{CASE REPORT}

A 2.5-year-old boy, MN, with atopic dermatitis, was referred to the clinic from the district hospital due to the suspicion of a celiac disease.

It is known from the family history that the child's mother suffers from neurofibromatosis type 1 and that the father's sister has celiac disease. The child was born from pregnancy II (complicated by gestational diabetes

\section{ADDRESS FOR CORRESPONDENCE:}

Dominika Wilczyńska, Department of Pediatrics, Allergology and Gastroenterology, Collegium Medicum Bydgoszcz, NCU Torun, Poland, e-mail: dominikapietrzniak@o2.pl 
and serological conflict), delivery II, at term, cesarean section (due to the lack of progression), with a birth weight $3340 \mathrm{~g}$ and Apgar rating of 10 points. The child was vaccinated according to the vaccination schedule. Gluten was introduced at 5 months, the child remained on the diet without any restrictions.

According to the mother, in the 2nd month preceding hospitalization, the boy was less active, often restless, periodically vomiting and passed 2-3 loose stools/ day, without pathological admixtures (previously normal stools). He was on a regular diet. During the last 3 months a weight gain of $3 \mathrm{~kg}$ was observed. A week before admission to the hospital, the mother noticed increased swelling of the lower limbs.

Upon admission to hospital, physical examination revealed: swelling of the eyelids, hands, lower limbs and a bloated, tender abdomen. Due to the features of the ileocecal intussusception in the abdominal ultrasound ("shooting target" sign), he was initially admitted to the Department of Pediatric Surgery, where a saline enema was performed, resulting in withdrawal of the intussusception, and then transferred to the pediatric ward with suspicion of nephrotic syndrome.

Laboratory tests showed abnormalities - hypoproteinemia, hypoalbulinemia, hypomagnesemia, hypocalcemia, hypophosphatemia, hypoglobulinemia, anemia, low iron levels and disorders of the coagulation system (a reduced prothrombin index and prolonged prothrombin time and increased INR). The results of laboratory tests are presented in Table 1. Low fT3 and fT 4 values were found on the basis of thyroid parameters. Tumor markers (AFP, CEA, LDH) were normal. Nephrotic syndrome (no proteinuria), cytomegaly, toxoplasmosis, yersiniosis, Epstein-Barr virus infection, hepatitis A, B and $\mathrm{C}$ and other viral and bacterial infections of the gastrointestinal tract were excluded. The ECHO showed a small amount of fluid in the pericardial sac.

The treatment included the supplementation of albumin, furosemide, vitamin $\mathrm{K}$ intravenously and infusion fluids, obtaining clinical and biochemical improvement.

Due to the suspicion of enteropathy, IgA class antibodies against transglutaminase were determined (IgA-TTG) and the result was abnormal (> $200 \mathrm{CU}$ ).

Consequently the child was referred to the Department of Paediatrics, Allergology and Gastroenterology, University Hospital No. 1 in Bydgoszcz for further diagnosis and treatment.

On admission, the general condition was assessed as being fairly good. Physical examination revealed pale skin, bloated abdomen and eczema lesions on the skin of the face and on the elbows. BMI $=13.89$ (between the $3-15^{\text {th }}$ percentile). Laboratory tests showed the following abnormalities: anemia and significantly elevated IgA-TTG (4965.5 CU).

A gastroscopy was performed, which revealed typical macroscopic lesions of celiac disease (significant paving of the mucosa in the duodenal bulb, later milling of the edges of folds, granulation of the mucosa). In the histopathological examination, the microscopic image corresponded to type $3 \mathrm{c}$ according to Marsh-Oberhuber (destructive type, complete atrophy of the villi - flat mucosa) $[10,13]$. Based on the overall clinical picture and the performed tests, the classic form of celiac disease was diagnosed.

Gluten-free diet was initiated immediately. Daily caloric intake was gradually increased to avoid the risk of a refeeding syndrome. After 6 days of a gluten-free diet the boy became more active and started making contact with other people. During hospitalization, a weight loss of $2.5 \mathrm{~kg}$ was observed (as a result of edema).

After six months, during the visit to the Gastroenterology Outpatient Clinic, the patient's general condition did not raise any suspicion. The child gained weight $3 \mathrm{~kg}$ and grew $5 \mathrm{~cm}$. The boy was symptom-free, the results of basic laboratory tests were normal and IgA-TTG were slightly elevated (Table 1).

\section{DISCUSSION}

American studies have revealed that in the last 50 years the number of new cases of celiac disease has increased more than 4 times, and in the last 15 years it has doubled $[6,14]$. It is estimated that the prevalence of celiac disease in the general population is $1 \%$ [2, 5-9]. Among children from 2.5 to 15 years of age, the incidence is 3 to 13 per $1000[15,16]$.

Among young children, celiac disease manifests itself most often as an overt form and the symptoms mainly concern the gastrointestinal tract and include chronic diarrhea, flatulence, abdominal pain as well as poor appetite and no expected weight gain [13]. In recent years, changes in the clinical picture of celiac disease have been observed - the incidence of full-blown classical celiac disease has decreased while the incidence of oligosymptomatic and asymptomatic forms has increased $[13,17,18]$. Currently, celiac disease among children manifests mainly as recurrent abdominal pain and growth disorders [19, 20]. In the literature from recent years, the incidence of classical celiac disease among all diagnosed pediatric patients was estimated at $42.2-51.3 \%$ [16, 18, 21-23].

According to literature, among children with classic celiac disease, the most common clinical picture is chronic diarrhea (87.8-90\% of patients), abdominal pain (45.4$70 \%)$, impaired physical development (54.3-65\%) and enlarged abdominal circumference (42.5-43.9\%) [16, 21].

In the presented case the clinical picture was dominated by rapidly increasing edema, therefore initially nephrotic syndrome was suspected which is the most common cause of generalized edema among children [24]. Additionally there was chronic diarrhea, a bloated abdomen, and behavioral changes (less activity, irritability), which however were mild. 
TABLE 1. The results of the patient's laboratory tests

\begin{tabular}{|c|c|c|c|c|}
\hline Test date & Range & $\begin{array}{c}\text { Before diagnosis } \\
\text { I }\end{array}$ & $\begin{array}{l}\text { Before diagnosis } \\
\text { II }\end{array}$ & $\begin{array}{c}\text { Six months after } \\
\text { diagnosis }\end{array}$ \\
\hline \multicolumn{5}{|l|}{ Blood count } \\
\hline $\mathrm{Hgb}$ & $11.0-14.0 \mathrm{~g} / \mathrm{dl}$ & $10.7 \downarrow$ & $10.3 \downarrow$ & 12.6 \\
\hline $\mathrm{RBC}$ & $3.9-4.9 \times 10^{6} / \mu \mathrm{l}$ & $4.01 \times 10^{6}$ & $3.86 \times 10^{6} \downarrow$ & $5.22 \times 10^{6}$ \\
\hline $\mathrm{HCT}$ & $32-42 \%$ & $34.1 \downarrow$ & $31.5 \downarrow$ & 37.9 \\
\hline MCV & $73-85 \mathrm{fl}$ & 85 & 81.6 & $72.6 \downarrow$ \\
\hline MCHC & $32-37 \mathrm{~g} / \mathrm{dl}$ & $31.4 \downarrow$ & 32.7 & 33.2 \\
\hline WBC & $5.5-15.5 \times 10^{3} / \mu \mathrm{l}$ & $10.94 \times 10^{3}$ & $11.96 \times 10^{3}$ & $8.27 \times 10^{3}$ \\
\hline \multicolumn{5}{|l|}{ lonogram } \\
\hline Potassium & $3.5-5.3 \mathrm{mmol} / \mathrm{l}$ & 3.75 & 4.2 & 4.2 \\
\hline Sodium & $132-145 \mathrm{mmol} / \mathrm{l}$ & 138.2 & 141.8 & 140.2 \\
\hline Chlorine & $96-111 \mathrm{mmol} / \mathrm{l}$ & 103.3 & 110.4 & 106.9 \\
\hline Magnesium & $0.73-1.07 \mathrm{mmol} / \mathrm{l}$ & $0.66 \downarrow$ & $0.72 \downarrow$ & 0.87 \\
\hline Phosphate & $1.29-2.26 \mathrm{mmol} / \mathrm{l}$ & $1.13 \downarrow$ & 1.55 & \\
\hline Calcium & $2.1-2.7 \mathrm{mmol} / \mathrm{l}$ & $2.02 \downarrow$ & 2.12 & 2.45 \\
\hline \multicolumn{5}{|l|}{ Gasometry } \\
\hline $\mathrm{pH}$ & $7.35-7.45$ & 7.428 & 7.467 & \\
\hline $\mathrm{pCO}_{2}$ & $35-45 \mathrm{~mm} \mathrm{Hg}$ & 40.4 & 31 & \\
\hline $\mathrm{pO}_{2}$ & $70-100 \mathrm{~mm} \mathrm{Hg}$ & 84.4 & 77.5 & \\
\hline $\mathrm{HCO}_{3}$ & $21-26 \mathrm{mmol} / \mathrm{l}$ & $26.7 \uparrow$ & 21.9 & \\
\hline $\mathrm{BE}$ & $-2-3 \mathrm{mmol} / \mathrm{l}$ & 2.3 & -0.7 & \\
\hline Sat & $95-98 \%$ & 96 & 96.3 & \\
\hline \multicolumn{5}{|l|}{ Coagulation system } \\
\hline $\mathrm{PT}$ & $9.4-13.8 \mathrm{~s}$ & $26.3 \uparrow$ & & 12.4 \\
\hline INR & $0.9-1.2$ & $2.55 \uparrow$ & & 1.12 \\
\hline Prothrombin index & $70-130 \%$ & $39 \downarrow$ & & 94.4 \\
\hline \multicolumn{5}{|l|}{ Serological markers of celiac disease } \\
\hline $\lg A$ antibodies against tissue transglutaminase & $\leq 19.9 \mathrm{CU}$ & $>200 \uparrow$ & $4965.5 \uparrow$ & $46.9 \uparrow$ \\
\hline \multicolumn{5}{|l|}{ Diagnostics of thyroid diseases } \\
\hline TSH & $0.70-5.97 \mu \mathrm{lU} / \mathrm{ml}$ & 2.14 & & \\
\hline fT3 & $3.10-6.80 \mathrm{pmol} / \mathrm{l}$ & $1.73 \downarrow$ & & \\
\hline fT4 & $12.00-22.00 \mathrm{pmol} / \mathrm{l}$ & $6.21 \downarrow$ & & \\
\hline \multicolumn{5}{|l|}{ Immunoglobulins } \\
\hline IgA total & $0.45-1.35 \mathrm{~g} / \mathrm{l}$ & $1.6 \uparrow$ & 1.14 & \\
\hline $\lg G$ & $500-1360 \mathrm{mg} / \mathrm{dl}$ & $216 \downarrow$ & & \\
\hline $\lg M$ & $40-190 \mathrm{mg} / \mathrm{dl}$ & $36 \downarrow$ & & \\
\hline \multicolumn{5}{|l|}{ 0thers } \\
\hline Total protein & $5.70-8.00 \mathrm{~g} / \mathrm{dl}$ & $3.97 \downarrow$ & & \\
\hline Albumin & $3.2-4.6 \mathrm{~g} / \mathrm{dl}$ & $2.15 \downarrow$ & 3.4 & 4.5 \\
\hline Iron & $3.2-4.6 \mathrm{~g} / \mathrm{dl}$ & $2.6 \downarrow$ & & \\
\hline Ferritin & $30-400 \mathrm{ng} / \mathrm{ml}$ & $12 \downarrow$ & & \\
\hline
\end{tabular}


According to available publications, edema among children with classical celiac disease occurs only in $3.5-10 \%[16,21]$ of the cases. Hypoalbuminemia is of the greatest importance here as it causes edema and leakage into body cavities (due to the reduced plasma oncotic pressure) [24]. Kuloglu et al. found that hypoalbuminemia was present in $14.2 \%$ of patient's cases with classic celiac disease [21].

In the differential diagnosis of generalized edema, apart from kidney disease (e.g. nephrotic syndrome), we consider also cardiological diseases (e.g. heart failure), liver diseases (e.g. cirrhosis), intestinal lymphangiectasia, hormonal disorders (e.g. hypothyroidism) and medications (e.g. corticosteroids).

The typical biochemical features of celiac disease are iron deficiency anemia and hypertransaminasemia $[16,23]$.

According to literature iron deficiency anemia occurs in $42.5 \%$ to $89 \%$ of children's cases with classical celiac disease $[16,21]$. We observed this in our patient's case.

Among children diagnosed with classical celiac disease, elevated values of transaminases are found quite often (in $35-40 \%$ of cases).

Of the electrolyte disturbances in the described boy's case, hypomagnesemia and hypocalcemia were found, which was not found in other studies [16, 24], only Kuloglu et al. [26] described hypocalcemia in 1.5\% of children's cases with classic celiac disease.

Data on coagulation disorders in the course of classical celiac disease may varry. They may not occur at all [24], or may affect up to $41.9 \%$ of patients [21]. They are characterized by extended prothrombin time, similar to the boy presented here. The mechanism of this disorder is associated with chronic inflammation in the small intestine and vitamin $\mathrm{K}$ malabsorption, which results in its deficiency and prolongation of prothrombin time [21].

Liver failure was also taken into account in the differential diagnosis due to hypoproteinemia with hypoalbuminemia and disturbances in the coagulation system, especially since prolongation of prothrombin time is the most sensitive indicator of liver failure. Due to the normalization of the above abnormalities, liver failure was excluded as a cause of generalized edema after starting a gluten-free diet.

Celiac disease can rarely manifest itself as a celiac crisis, which is a life-threatening condition (mortality estimated at 90\%), characterized by increased diarrhea, dehydration, metabolic disturbances (hypokalaemia, hypomagnesaemia, hypocalcaemia, hypoproteinaemia, hypophosphataemia and metabolic acidosis) $[11,20$, 25-27] Taking into account the overall clinical picture of the presented case (intussusception, generalized edema, hypoproteinemia and electrolyte disturbances), very similar to case report described by Catessi et al. [28], a diagnosis of celiac crisis was made.
Due to the general condition of the patient (despite the lack of a histopathological result at the time), it was decided to immediately start a gluten-free and lactose-free diet.

In the initial period of treatment of celiac disease, especially in cases with chronic diarrhea, enteropathy and lactose intolerance secondary to celiac disease it is often necessary to follow a diet with elimination of lactose. Some patients require additional selective iron and/or calcium supplementation, less often with complex multivitamins or vitamin and mineral preparations. In a case of severe malnutrition, in order to provide the necessary nutrients, it may be justified to temporarily use a parenteral nutritional treatment. It is necessary to gradually increase the daily calories to avoid the risk of a refeeding syndrome $[28,29]$.

In the described case, due to the observed rapid improvement of the clinical condition after the gluten-free diet (improvement of appetite and activity, normalization of consistency and number of stools, reduction of edema), the implementation of this form of nutritional support was not necessary. Rapid improvement in the child's clinical condition was an additional confirmation of the treatment's accuracy and the correct diagnosis of the disease.

Due to the unusual clinical course of celiac disease in this case, i.e. edema and hypoalbuminemia with moderate symptoms from the gastrointestinal tract, it was decided to perform gastroscopy with samples for histopathological examination, despite the determination of IgA-TTG 10 times above the norm (according to the guidlines from 2012 year, just before the new ones appeared ).

However, in 2020, new ESPGHAN guidelines were published, according to which for the diagnosis of celiac disease in both asymptomatic (screening) and symptomatic patients, you can opt out for histopatological examination of biopsies taken from duodenum and genetic tests, in the case of the determination of IgATTG 10 times above the norm. and an increased concentration of anti-endomial antibodies in the IgA class (EMA-IgA) in the blood sample collected a second time. Therefore, in this case, it would be enough to confirm the diagnosis of celiac disease with the EMAIgA determination. Screening for celiac disease (total $\operatorname{IgA}$ and $\operatorname{IgA-TTG)}$ is recommended to first-degree relatives [30].

\section{CONCLUSIONS}

In a child with generalized edema, dehydration, metabolic disorders of unclear etiology, the differential diagnosis should include the classic form of celiac disease.

\section{DISCLOSURE}

The authors declare no conflict of interest. 


\section{REFERENCES}

1. Husby S, Koletzko S, Korponay-Szabo IR, et al. ESPGHAN guidelines for the diagnosis of coeliac disease in children and adolescents. An evidence - based approach. J Pediatr Gastroenterol Nutr 2012; 54: 136-160.

2. Ludvigsson JF, Leffler DA, Bai JC, et al. The Oslo definitions for coeliac disease and related terms. Gut 2013; 62: 43-52.

3. Fasano A, Catassi C. Celiac disease. N Engl J Med 2012; 367: 2419-2426.

4. Beniwal N, Gaurav A, Chandra KC. Celiac Disease in Children with Severe Acute Malnutrition (SAM): A Hospital Based Study Neetu. Indian J Pediatr 2017; 84: 339 - 343.

5. Lebwohl B, Sanders DS, Green PHR; Coeliac disease; Lancet 2018; 391: 70-81.

6. Rubio-Tapia A, Ludvigsson JF, Brantner TL et al.; The prevalence of celiac disease in the United States. Am J Gastroenterol 2012; 107: $1538-44$.

7. Mustalahti K, Catassi C, Reunanen A et al.; The prevalence of celiac disease in Europe: Results of a centralized,international mass screening project. Ann Med 2010; 42: 587-595.

8. Choung RS, Larson SA, Khaleghi S et al.; Prevalence and morbidity of undiagnosed celiac disease from a community-based study. Gastroenterology 2017; 152: 830-39

9. Babar MI, Ahmad I, Rao MS et al.; Celiac Disease and Celiac Crisis in Children; Journal of the College of Physicians and Surgeons Pakistan 2011; 21: 487-490

10. Alharbi AO, Alharbi MS. Pediatric Patient with a celiac crisis (rare presentation of a common disease), case report and literature review. Journal of Case Report and Studies 2018; 6: 1-6.

11. Downey L, Houten R, Murch S, et al. Recognition, assessment, and management of coeliac disease: summary of updated NICE guidance. BMJ 2015; 351: h4513.

12. Walia A, Thapa BR. Celiac crisis. Indian Pediatr 2005; 42: 1169.

13. Czerwionka-Szaflarska M, Szaflarska-Popławska A, Muller L. Choroba trzewna dzieci i dorosłych. Alergia 2006; 2: 20-24.

14. Catassi C, Kryszak D, Bhatti B, et al. Natural history of celiac disease autoimmunity in a USA cohort followed since 1974. Ann med 2010; 42: 530-538.

15. Hill ID, Dirks MH, Liptath GS. Guideline for the diagnosis and treatment of celiac disease in children: recommendations of the North American Society for Pediatric Gastroenterology, Hepatology and Nutrition. J Pediatr Gatroenterol Nutr 2005; 40: 1-19.

16. Iwańczak B, Matusiewicz K, Iwańczak F. Clinical picture of classical, atypical and silent celiac disease in children and adolescents. Adv Clin Exp Med 2013; 22: 667-673.

17. Rampertab SD, Pooran N, Brar P, et al. Trends in the presentation of celiac disease. Am J Med 2006; 119: e9-14.

18. Gokce S, Arslantas E. The changing face and clinical features of celiac disease in children. Pediatr Int 2015; 57: 107-112.

19. Beitnes AR, Vikskjold FB, Jóhannesdóttir GB, et al. Symptoms and mucosal changes stable during rapid increase of Pediatric Celiac Disease in Norway. J Pediatr Gastroenterol Nutr 2017; 64: 586-591.

20. Radlovic N, Lekovic Z, Radlovic V, et al. Celiac crisis in children in Serbia. Italian Journal of Pediatrics 2016; 42: 25.

21. Kuloglu Z, Kirsachoglu CT, Kansu A, et al. Celiac disease: presentation of 109 children. Yonsei Med J 2009; 50: 617-623.

22. Altamimi E. Celiac Disease in South Jordan. Pediatr Gastroenterol Hepatol Nutr 2017; 20: 222-226.

23. Szaflarska-Popławska A. Patologia wątroby w celiakii - badania własne i przegląd piśmiennictwa. Przegl Gastroenterol 2011; 6: 259-266.
24. Butorac Ahel, Suborat Dezulović M, Palcevski G. Generalized edema wih hypoproteinemia as initial presentation of celiac disease in a 3-year-old boy: case report. Paediatr Croat 2015; 59: 181-184.

25. Waheed N, Cheema HA, Suleman H, et al. Celiac crisis: a rare or rarely recognized disease. J Ayub Med Coll Abbottabad 2016; 28 : 672-675.

26. Balaban DV, Dima A, Jurcut C, et al. Celiac crisis, a rare occurrence in adult celiac disease: A systematic review. World J Clin Cases 2019; 7: 311-319.

27. Mones RL, Atienza KV, Youssef NN, et al. Celiac crisis in the modern era. J Pediatr Gastroenterol Nutr 2007; 45: 480-483.

28. Catassi GN, Vallorani M, Cerioni F, et al. A negative fallout of COVID - 19 lockdown in Italy: Life - threatening delay in the diagnosis of celiac disease. Dig Liver Dis 2020; 52: 1092-1093.

29. Agarwal J, Poddar U, Yachha SK, et al. Refeeding syndrome in children in developing countries who have celiac disease. J Pediatr Gastroenterol Nutr 2012; 54: 521-524.

30. Cukrowska B. Celiakia - zasady diagnostyki według nowych wytycznych ESPGHAN 2020. Monografia. Pediatria po Dyplomie 2020; 3: 12-15. 